\title{
PERAWATAN PREVENTIF MESIN BUBUT MENGGUNAKAN METODE ANALISIS GETARAN DALAM BERBAGAI KONDISI KECEPATAN SPINDLE
}

\author{
Heryanto B.S. ${ }^{1}$, Kasijanto $^{2}$ \\ ${ }^{1}$ Department of Mechanical Engineering, State Polytechnic of Malang, Jalan Soekarno Hatta No 09, Malang 65141, Indonesia \\ 1heryantobs@polinema.ac.id
}

\begin{abstract}
Abstrak - Penelitian ini mengusulkan sebuah gagasan baru metode perawatan preventif mesin bubut dengan menganalisis getaran pada gear box kepala tetap mesin bubut maximat. Dari hasil getaran yang terjadi dilakukan pemeriksaan pada minyak pelumas, kecacatan roda gigi dan bearing yang ada selanjutnya dilakukan langkah-langkah perbaikan baik pada gear maupun pada bearing dan penggantian minyak pelumas. Untuk mengetahui besar getaran yang terjadi pada mesin bubut maximat ini, dilakukan variasi putaran sebesar 1000 (rpm), 1500 (rpm) dan 2000 (rpm). Nilai rata-rata amplitudo tertinggi pada putaran mesin 1000 RPM adalah pada mesin Bu04 dengan nilai sebesar $0.034 \mathrm{~mm} / \mathrm{s}$ RMS sedangkan nilai terendah didapat pada mesin bubut Bu03 dengan nilai sebesar $0.029 \mathrm{~mm} / \mathrm{s}$ RMS. Pada putaran mesin $1500 \mathrm{RPM}$, nilai rata-rata amplitudo tertinggi didapatkan pada mesin bubut Bu03 dengan nilai sebesar $0.045 \mathrm{~mm} / \mathrm{s}$ RMS. Sedangkan pada mesin bubut Bu02 dengan nilai sebesar $0.032 \mathrm{~mm} / \mathrm{s}$ RMS. Pada putaran mesin 2000 RPM, nilai rata-rata amplitudo tertinggi didapatkan pada mesin bubut Bu03 dengan nilai sebesar $0.069 \mathrm{~mm} / \mathrm{s}$ RMS. Sedangkan nilai terendah didapat pada mesin bubut Bu02 dengan nilai sebesar 0.050 $\mathrm{mm} / \mathrm{s}$ RMS. Semakin rendah getaran mesin bubut maka semakin optimal hasil dari pembubutan. Terdapat pengaruh antara besar putaran mesin terhadap getaran yang terjadi. Mesin bubut dengan tingkat amplitudo tinggi menandakan bahwa terdapat komponen yang perlu diperhatikan.
\end{abstract}

Kata Kunci-Analisis Getaran; Mesin Bubut; Perawatan Preventif

\begin{abstract}
This research proposes a new idea of the preventive maintenance method of the lathe by analyzing the vibration on the fixed gear gearbox of the Maximat lathe. From the results of the vibrations that occur, checks are carried out on the lubricating oil, disability of the existing gears and bearings, and then repairing the gear and bearing and replacing the lubricating oil. To find out the magnitude of vibration that occurs in this maximat lathe, rotation variations are carried out by 1000 (rpm), 1500 (rpm) and 2000 (rpm). The highest average amplitude value at 1000 RPM engine speed is on the Bu04 machine with a value of $0.034 \mathrm{~mm} / \mathrm{s}$ RMS while the lowest value is obtained on the Bu03 lathe with a value of $0.029 \mathrm{~mm} / \mathrm{s} \mathrm{RMS}$. At 1500 RPM engine speed, the highest average amplitude value is obtained on the Bu03 lathe with a value of $0.045 \mathrm{~mm} / \mathrm{s}$ RMS. On the Bu02 lathe with a value of $0.032 \mathrm{~mm} / \mathrm{s}$ RMS. At $2000 \mathrm{RPM}$ engine speed, the highest average value of amplitude was obtained in the Bu03 lathe with a value of $0.069 \mathrm{~mm} / \mathrm{s}$ RMS. While the lowest value obtained on the Bu02 lathe with a value of $0.050 \mathrm{~mm} / \mathrm{s}$ RMS. The lower the vibration of the lathe, the more optimal the results of turning. There is an influence between the speed of the engine against the vibrations that occur. Lathe with a high amplitude level indicates that there are components that need attention.
\end{abstract}

Keywords - vibration analysis; lathe machine; preventif maintenance

\section{PENDAHULUAN}

Efek getaran berpengaruh besar pada mesin perkakas. Getaran yang tinggi berimplikasi pada hasil pekerjaan yang dilakukan, umur pahat dan umur mesin. Getaran yang tinggi akan menyebabkan kualitas benda kerja menjadi kurang bagus, umur pahat menjadi rendah (mudah tumpul) dan mesin tidak tahan lama (break down time). Getaran mesin perkakas berpengaruh terhadap mesin perkakas itu sendiri, kondisi pemotongan, getaran benda kerja dan umur pahat. Pengaruh getaran pada kondisi pemotongan dapat dilihat dari perubahan geram yang mana akibat perubahan gaya pemotongan juga menghasilkan perubahan bentuk geram. Getaran tinggi dapat disebabkan oleh kurangnya pelumas, perubahan pada pelumas, adanya cacat pada gear dan adanya cacat pada bearing.[1]

Amplitudo getaran alat mesin harus relatif rendah untuk mempertahankan toleransi dimensi dan untuk memberikan permukaan akhir yang dapat diterima dari benda kerja mesin.[2]

Batas getaran didasarkan pada pengalaman pabrikan dan dipilih sebagai tipikal yang diperlukan pada peralatan mesin untuk memperoleh analisis. Batasan ini digunakan sebagai panduan batas untuk spesifikasi pemesinan yang ketat. Batas getaran berada dalam unit tertentu berbeda-beda, karena perhatian utama untuk getaran alat mesin adalah gerakan relatif antara benda kerja dan pahat. Gerakan relatif ini 
dibandingkan dengan permukaan akhir yang ditentukan dan toleransi dimensi. Ketika mesin kritis dengan pekerjaan berat, keputusan untuk memperbaiki sering kali sangat sulit dibuat. Karenanya, ketika menetapkan tingkat kondisi mesin yang dapat diterima, pengalaman dan faktor-faktor seperti keselamatan, biaya tenaga kerja, biaya waktu henti dan kekritisan alat berat perlu dipertimbangkan.[3]

Pengukuran getaran pada mesin bubut digunakan untuk melakukan tindakan awal dari kerusakan pada gear, bearing dan kurangnya pelumas atau telah berubahnya tingkat viskositas dari pelumas itu sendiri [4],[5]. Sehinga break down pada mesin dapat dihindari sedini mungkin, dan mesin selalu siap untuk dipakai

Penelitian ini mengusulkan sebuah gagasan baru perawatan preventif dengan menganalisis getaran pada gear box kepala tetap mesin bubut maximat dengan menggunakan vibrator tester. Dari hasil getaran yang terjadi dilakukan pemeriksaan pada minyak pelumas, kecacatan roda gigi dan bearing yang ada selanjutnya dilakukan langkah langkah perbaikan baik pada gear maupun pada bearing dan penggantian minyak pelumas. Pengaruh kecepatan pemakanan dianalisis terhadap getaran yang terjadi. Analisis secara menyeluruh pada 3 variasi kecepatan spindle dilakukan pada 5 mesin bubut yang memiliki kondisi berbeda untuk dapat dibandingkan dan sekaligus menguji kondisi dari mesin bubut.

\section{METODE}

Penelitian ini menggunakan metode penelitian eksperimental dengan mengambil tema: Teknologi dan Ketahanan Energi. Penelitian dilaksanakan di Bengkel Mekanik 2 Mesin Perkakas Gedung Bengkel Teknik Mesin Politeknik Negeri Malang. Populasi: Mesin Bubut Maximat V13. Sampel: Getaran gear box kepala tetap mesin bubut maximat V13. Variabel yang digunakan dalam penelitian ini adalah sebagai berikut: Variabel bebas dalam penelitian ini yaitu variasi besar putaran mesin, yaitu $1000 \mathrm{rpm}, 1500 \mathrm{rpm}$, dan $2000 \mathrm{rpm}$. Variabel terikat dalam penelitian ini adalah besar getaran yang terjadi pada mesin bubut maximat V13. Beberapa parameter yang dijaga konstan selama pengujian adalah: Kedalaman pemakanan 0.5 ( $\mathrm{mm})$ dan Panjang pemakanan 100 (mm). Untuk dapat menganalisis besar getaran yang terjadi pada masing-masing spesimen dan variasi putaran mesin, digunakan vibration meter yang diletakkan pada bagian headstock $5 \mathrm{~cm}$ dari diameter luar chuck. Hal ini dilakukan untuk mendapatkan nilai getaran akhir dari sistem transmisi roda gigi menuju spindle. Sehingga terdapat total 30 data pada 5 jenis mesin bubut dan 3 variasi putaran mesin dengan masing-masing pengambilan data sebanyak 2 kali.

Data diambil pada rentang frekuensi $0-5000 \mathrm{~Hz}$ dengan penyimpanan data 250 sampel setiap 5 detik. Data dari pengukuran kemudian dieksport pada komputer untuk diolah lebih lanjut. Pengolahan data menggunakan metode FFT (Fast Fourier Transform) dengan software Octave untuk mendapatkan grafik domain frekuensi lebih detail. Software Octave merupakan piranti penghitungan berbasis matriks dengan lisensi Open Source. Berikut ini adalah koding untuk melakukan plot dari hasil perhitungan FFT pada setiap data. [6]

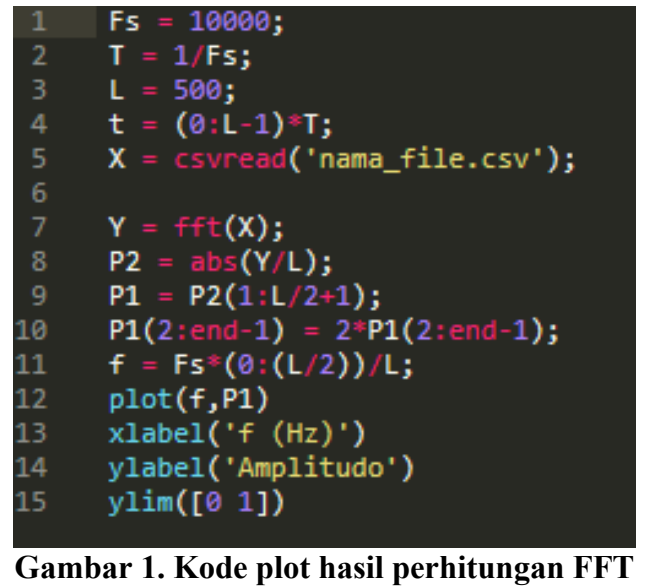

Pada penelitian ini dilakukan proses turning dengan menggunakan mesin bubut Maximat V13. Pahat yang digunakan adalah pahat HSS dan material yang dibubut adalah ST.37. Adapun metode yang digunakan sebagai berikut:

1. Menentukan jenis dan ukuran material benda kerja. Material yang digunakan yaitu poros silinder pejal baja ST 37 diameter $30 \mathrm{~mm}$ dan panjang $150 \mathrm{~mm}$. sebelum benda kerja digunakan untuk meneliti, permukaan diproses terlebih dahulu untuk mendapatkan ukuran yang diinginkan satu dengan yang lainnya.

2. Menentukan parameter pengujian yang meliputi putaran, kedalaman pemakanan, dan laju pemakanan. Kedalaman pemakanan dibuat konstan sebesar $0.5 \mathrm{~mm}$ dan juga untuk besarnya laju pemakanan digunakan sebesar $0.01 \mathrm{~mm} /$ put. Untuk besarnya putaran mesin dibuat tiga variasi yaitu $1000 \mathrm{rpm}, 1500 \mathrm{rpm}$, dan $2000 \mathrm{rpm}$.

3. Mengukur getaran dengan menggunakan vibrator test.

4. Menentukan dan memasang posisi probe

5. Melakukan proses turning dan pengukuran getaran. Data getaran yang diambil yaitu pada saat telah stabil. Pengujian dilakukan sebanyak dua kali untuk masingmasing posisi.

Melakukan analisa dari hasil pengujian dan membuat kesimpulan.

HASIL DAN DISKUSI

Domain Frekuensi pada Mesin Bubut Bu01

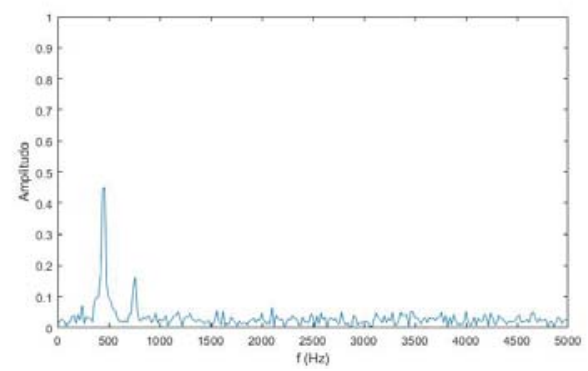

(a) Data 1 


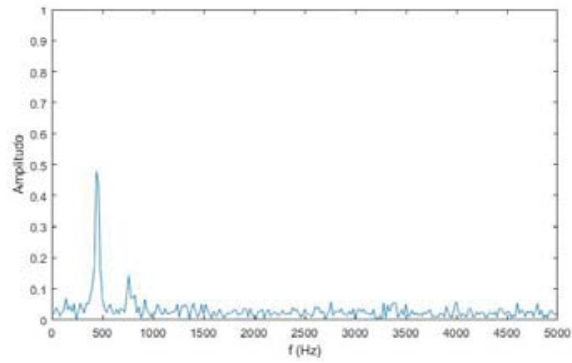

(b) Data 2

Gambar 2. Domain frekuensi pada Bu01 1000 RPM

Berdasarkan data domain frekuensi pada Bu01 1000 RPM dari kedua pengambilan data didapatkan rata-rata keseluruhan amplitudo sebesar $0.031 \mathrm{~mm} / \mathrm{s}$ RMS dan rata-rata amplitudo tertinggi sebesar $0.464 \mathrm{~mm} / \mathrm{s}$ RMS. Frekuensi pribadi pada variasi ini adalah $\pm 450 \mathrm{~Hz}$. Besar amplitudo tidak terlampau besar pada putaran mesin 1000 RPM.

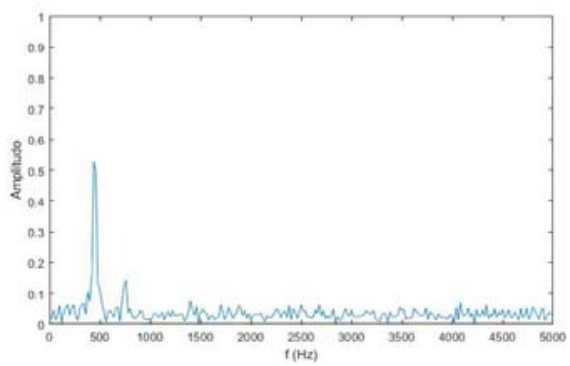

(a) Data 1

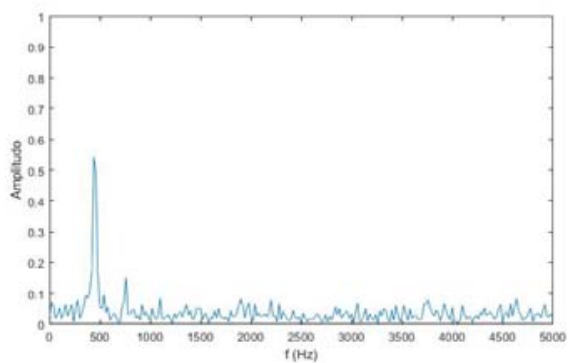

(b) Data 2

Gambar 3. Domain frekuensi pada Bu01 1500 RPM

Berdasarkan data domain frekuensi pada Bu01 1500 RPM dari kedua pengambilan data didapatkan rata-rata keseluruhan amplitudo sebesar $0.039 \mathrm{~mm} / \mathrm{s}$ RMS dan rata-rata amplitudo tertinggi sebesar $0.535 \mathrm{~mm} / \mathrm{s}$ RMS. Frekuensi dominan pada variasi ini adalah $\pm 440 \mathrm{~Hz}$. Besar rata-rata amplitudo meningkat sebesar 0.007 dibandingkan sebelumnya seiring dengan adanya peningkatan putaran mesin sebesar 500 RPM.

Heryanto B. S.: Perawatan Preventif Mesin Bubut ...

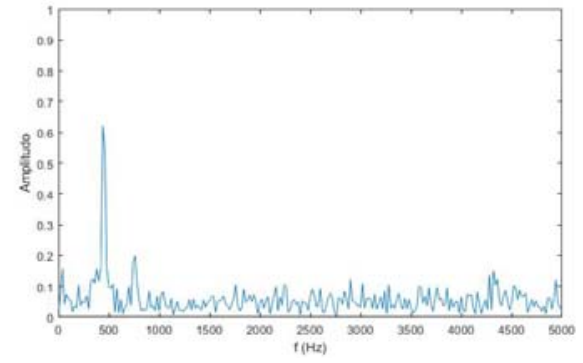

(a) Data 1

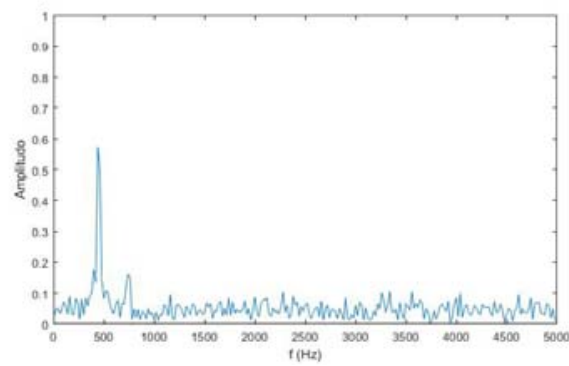

(b) Data 2

Gambar 4. Domain frekuensi pada Bu01 2000 RPM

Berdasarkan data domain frekuensi pada Bu01 2000 RPM dari kedua pengambilan data didapatkan rata-rata keseluruhan amplitudo sebesar $0.056 \mathrm{~mm} / \mathrm{s}$ RMS dan rata-rata amplitudo tertinggi sebesar $0.596 \mathrm{~mm} / \mathrm{s}$ RMS. Frekuensi dominan pada variasi ini adalah $\pm 440 \mathrm{~Hz}$. Besar rata-rata amplitudo meningkat sebesar $0.017 \mathrm{~mm} / \mathrm{s}$ RMS dibandingkan sebelumnya seiring dengan adanya peningkatan putaran mesin sebesar 500 RPM.

Pengaruh Putaran Mesin terhadap Rata-Rata Amplitudo

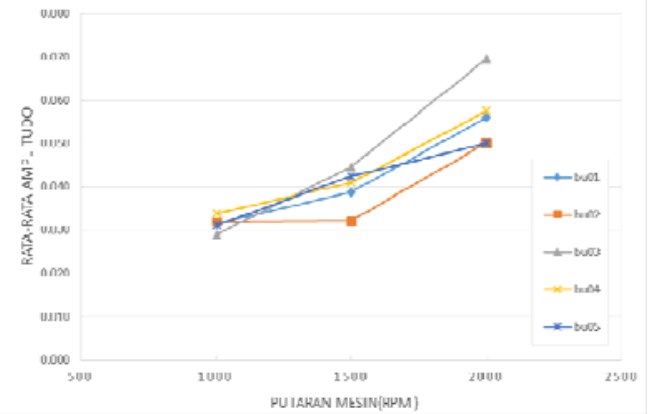

Gambar 5. Pengaruh putaran mesin terhadap rata-rata amplitudo

Pada keseluruhan variasi terlihat bahwa semakin besar putaran mesin berdampak pada getaran yang semakin besar. Hal ini dapat diidentifikasi dari besar amplitudo yang terjadi. Namun pada variasi putaran mesin 1000 dan 1500 mesin bubut Bu02 tidak terdapat peningkatan rata-rata amplitudo, akan tetapi jika ditinjau dari amplitudo maksimum pada frekuensi pribadi mesin didapatkan peningkatan. Hal ini dikarenakan data rata-rata diambil dari akumulasi ampitudo pada keseluruhan frekuensi yakni dari 0-5000 Hz. 
Dari Gambar 5 dapat diamati, bahwa pada putaran mesin 1000 RPM, nilai rata-rata amplitudo tertinggi didapatkan pada mesin bubut Bu04 dengan nilai sebesar $0.034 \mathrm{~mm} / \mathrm{s}$ RMS, sedangkan nilai rata-rata amplitudo terendah didapat pada mesin bubut Bu03 dengan nilai sebesar $0.029 \mathrm{~mm} / \mathrm{s}$ RMS Pada putaran mesin 1500 RPM, nilai rata-rata amplitudo tertinggi didapatkan pada mesin bubut $\mathrm{Bu} 03$ dengan nilai sebesar $0.045 \mathrm{~mm} / \mathrm{s}$ RMS, sedangkan nilai rata-rata amplitudo terendah didapat pada mesin bubut $\mathrm{Bu} 02$ dengan nilai sebesar 0.032. Pada putaran mesin 2000 RPM, nilai rata-rata amplitudo tertinggi didapatkan pada mesin bubut $\mathrm{Bu} 03$ dengan nilai sebesar $0.069 \mathrm{~mm} / \mathrm{s}$ RMS, sedangkan nilai ratarata amplitudo terendah didapat pada mesin bubut $\mathrm{Bu} 02$ dengan nilai sebesar $0.050 \mathrm{~mm} / \mathrm{s}$ RMS.

\section{Pengaruh Putaran Mesin terhadap Amplitudo Maksimal}

Amplitudo maksimal didapatkan dari data amplitudo tertinggi pada frekuensi tertentu. Amplitudo maksimal mewakili kecenderungan simpangan terjauh pada gelombang pembacaan data getaran mesin bubut.

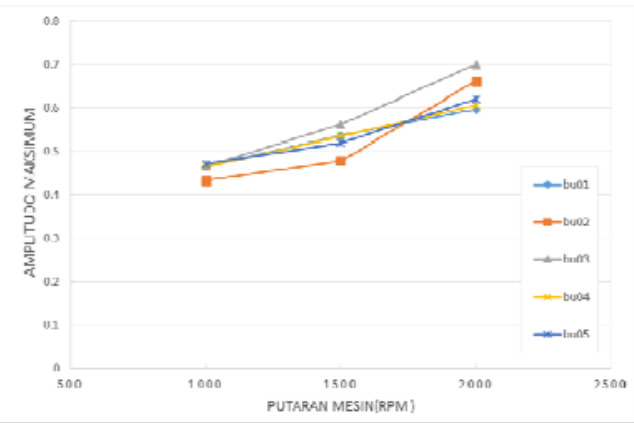

Gambar 6. Pengaruh putaran mesin terhadap amplitudo maksimal

Dari Gambar 6 dapat diamati bahwa pada putaran mesin 1000 RPM, nilai amplitudo tertinggi didapatkan pada mesin bubut Bu05 dengan nilai sebesar $0.471 \mathrm{~mm} / \mathrm{s}$ RMS, sedangkan nilai amplitudo terendah didapat pada mesin bubut $\mathrm{Bu} 02$ dengan nilai sebesar $0.432 \mathrm{~mm} / \mathrm{s}$ RMS. Hal ini menunjukkan bahwa kondisi terbaik pada putaran mesin 1000 RPM adalah pada mesin bubut $\mathrm{Bu} 02$, sedangkan pada mesin $\mathrm{Bu} 05$ getaran yang tinggi dapat mengakibatkan benda kerja yang digunakan memiliki nilai kehalusan permukaan yang relatif lebih kasar/tidak rata.

Pada putaran mesin 1500 RPM, nilai amplitudo tertinggi didapatkan pada mesin bubut Bu03 dengan nilai sebesar 0.561 $\mathrm{mm} / \mathrm{s}$ RMS, sedangkan nilai amplitudo terendah didapat pada mesin bubut Bu02 dengan nilai sebesar $0.477 \mathrm{~mm} / \mathrm{s}$ RMS. Hal ini menunjukkan bahwa kondisi terbaik pada putaran mesin 1000 RPM adalah pada mesin bubut Bu02, sedangkan pada mesin Bu03 getaran yang tinggi dapat mengakibatkan benda kerja yang digunakan memiliki nilai kehalusan permukaan yang relatif lebih kasar/tidak rata.

Pada putaran mesin 2000 RPM, nilai amplitudo tertinggi didapatkan pada mesin bubut Bu03 dengan nilai sebesar 0.699 $\mathrm{mm} / \mathrm{s}$ RMS, sedangkan nilai amplitudo terendah didapat pada mesin bubut Bu01 dengan nilai sebesar $0.596 \mathrm{~mm} / \mathrm{s}$ RMS. Hal ini menunjukkan bahwa kondisi terbaik pada putaran mesin 1000 RPM adalah pada mesin bubut Bu01, sedangkan pada mesin $\mathrm{Bu} 03$ getaran yang tinggi dapat mengakibatkan benda kerja yang digunakan memiliki nilai kehalusan permukaan yang relatif lebih kasar/tidak rata.

Dari keseluruhan data jika dianalisis lebih lanjut maka pada setiap variasi putaran mesin menunjukkan bahwa nilai getaran yang terjadi masih dalam ambang yang diperbolehkan untuk dioperasikan. Meskipun demikian, karakteristik setiap mesin bubut pada setiap variasi putaran mesin memiliki respon yang berbeda-beda.

\section{KESIMPULAN}

Dari keseluruhan data didapatkan bahwa pada setiap variasi putaran mesin, nilai getaran yang terjadi masih dalam ambang yang diperbolehkan untuk dioperasikan. Meskipun demikian, karakteristik setiap mesin bubut pada setiap variasi putaran mesin memiliki respon yang berbeda-beda.

Dari hasil analisis data dapat ditarik beberapa simpulan antara lain berikut ini:

a) Analisis getaran dapat dijadikan sebagai salah satu metode untuk melaksanakan preventive maintenance dengan acuan nilai amplitudo atau simpangan terjauh pada getaran yang terjadi.

b) Terdapat pengaruh antara besar putaran mesin terhadap getaran yang terjadi. Semakin besar putaran mesin akan mengakibatkan getaran mesin yang semakin besar pula.

c) Nilai rata-rata amplitudo tertinggi pada putaran mesin 1000 RPM adalah pada mesin Bu04 dengan nilai sebesar $0.034 \mathrm{~mm} / \mathrm{s}$ RMS sedangkan nilai terendah didapat pada mesin bubut Bu03 dengan nilai sebesar $0.029 \mathrm{~mm} / \mathrm{s}$ RMS. Pada putaran mesin 1500 RPM, nilai rata-rata amplitudo tertinggi didapatkan pada mesin bubut $\mathrm{Bu} 03$ dengan nilai sebesar $0.045 \mathrm{~mm} / \mathrm{s}$ RMS, sedangkan pada mesin bubut $\mathrm{Bu} 02$ dengan nilai sebesar $0.032 \mathrm{~mm} / \mathrm{s}$ RMS. Pada putaran mesin 2000 RPM, nilai rata-rata amplitudo tertinggi didapatkan pada mesin bubut $\mathrm{Bu} 03$ dengan nilai sebesar $0.069 \mathrm{~mm} / \mathrm{s}$ RMS, sedangkan nilai terendah didapat pada mesin bubut $\mathrm{Bu} 02$ dengan nilai sebesar $0.050 \mathrm{~mm} / \mathrm{s}$ RMS. Semakin rendah getaran mesin bubut maka semakin optimal hasil dari pembubutan.

\section{UCAPAN TERIMA KASIH}

Penulis menyampaikan terima kasih kepada Polinema yang telah membiayai penelitian ini dengan dana DIPA Polinema Tahun 2019.

\section{REFERENSI}

[1] Girdhar, P., 2004, Practical machinery Vibration Analysis and Predictive Maintenance, 1st ed., Elsevier. 
[2] Koten, V.K., 2008, Analisis Pengaruh Kondisi Pemotongan pada Mesin Bubut Terhadap Amplitudo Getaran Pahat dan Kekasaran Permukaan Benda Kerja, Proceeding Seminar Nasional Mesin dan Industri. Vol.4, p. 319 - 327, Jakarta.

[3] [Kibbe, R.R. et.al., 2001, Machine Tool Practices, 7th ed., Prentice Hall.

[4] Sugondo, Amelia. et. al., 2008, Studi Pengaruh Kedalaman Pemakanan terhadap Getaran dengan Menggunakan Mesin Bubut Chien Yeh CY 800 Gf, Seminar Nasional -VII Rekayasa dan Aplikasi Teknik Mesin di Industri Kampus ITENAS, Bandung

[5] Lin J. and Zuo M. J (2003), "Gear box fault diagnosis using adaptive wavelet filter", Mechanical Systems and Signal Processing, Vol. 17(6), pp.1259-1269

[6] Blevins, R. D., Formulas for Natural Frequency and Mode Shape, Van Nostrand, (1979). 